\title{
Inhibitory effects of reinforcement and a model of fixed-interval performances
}

\author{
KENNETH J. KELLER \\ Maryland Psychiatric Research Center, Baltimore, Maryland 21228
}

\begin{abstract}
Catania's version of Herrnstein's response-reinforcement input-output function is derived from two assumptions about reinforcement: (1) that reinforcers excite responses upon which they are contingent in proportion to the reinforcement, and (2) that reinforcers inhibit all responding in proportion to the reinforcement and in proportion to ongoing responding. In choice situations, unlike Herrnstein's interpretation of the $r_{o}$ parameter, these assumptions predict the empirical matching law without first assuming it. The additional assumptions of exponential growth of a reinforcer's strength over a fixed interval, and of proportionate timing of intervals, lead to a mathematical description of fixed-interval responding. The fixed-interval scallop results from the simultaneous growth of the reinforcer's excitatory and inhibitory functions. An attempt is made to derive variable-interval schedule performance from the fixed-interval case.
\end{abstract}

An advance in the quantitative study of behavior has been the specification of what might be called the response-reinforcement input-output function, that is, the function describing the behavior generated by contingent reinforcement. Perhaps the major contribution to this effort has been Herrnstein's equation (Herrnstein, 1970, 1974); in a single-response, no-choice situation:

$$
\mathrm{R}=\frac{\mathrm{kr}}{\mathrm{r}+\mathrm{r}_{\mathrm{o}}}
$$

where $\mathbf{R}$ is an appropriate response measure (response rate in free-operant studies), $\mathrm{r}$ is obtained reinforcement (usually reinforcement rate, but it could be amount, immediacy, or any other reinforcement parameter), and $k$ and $r_{o}$ are empirically determined constants. While $k$ is simply a units constant, $r_{o}$ has an interpretation central to this paper.

The Herrnstein equation is easily generalized to choice situations. For situations involving two responses, $\mathbf{R}_{\mathbf{1}}$ and $\mathbf{R}_{\mathbf{2}}$ :

$$
R_{1}=\frac{k r_{1}}{r_{1}+r_{2}+r_{0}} ; R_{2}=\frac{k r_{2}}{r_{1}+r_{2}+r_{0}}
$$

and so

$$
\frac{R_{1}}{R_{1}+R_{2}}=\frac{r_{1}}{r_{1}+r_{2}}
$$

Thanks are due to A. C. Catania, H. Rachlin, P. Tueting, and A. Wagman for comments on earlier drafts of this paper. Reprints may be obtained from the author, Maryland Psychiatric Research Center, Box 3235, Baltimore, Maryland 21228.
Equation 2 is the matching law, an empirical law antedating Herrnstein's equation (Baum, 1974; Catania, 1963a, 1963b; Chung \& Herrnstein, 1967; Herrnstein, 1961; Killeen, 1975; Rachlin, 1971).

Although Equation 1 was originally derived from animal experiments usually employing variableinterval reinforcement schedules, the equation is more general in that it contacts other areas of investigation. As Luce (1977) pointed out, Herrnstein's equation empirically realizes the basic choice axiom that figures in much theoretical work on preference. In addition, the equation describes the results of a wider range of experiments, with a broader range of response and reinforcement variables, than those from which it was originally derived (deVilliers, 1977; deVilliers \& Herrnstein, 1976). And, although alternatives to the Herrnstein equation have been proposed (e.g., McDowell \& Kessel, 1979; Nevin, 1974; Rachlin, 1978; Staddon, 1977), Equation 1 can be thought of as the most generally successful.

At issue, however, is the interpretation of the $r_{0}$ parameter. After briefly describing the standard interpretation, the present paper explores the quantitative consequences of an alternative interpretation first suggested by Catania (1973). This alternative is then turned back upon the original operant work in an attempt to formulate a quantitative description of a resistant problem, the form of the fixed-interval scallop.

\section{Standard Interpretation}

Herrnstein's interpretation of the $r_{0}$ constant is a logical extension of the matching law. In choice situations, animals distribute their responses in proportion to the distribution of reinforcers. It is therefore assumed that in a single-response situation, animals distribute their responses between the experimentally 
designated response and other unspecified responses in proportion to experimentally programmed reinforcers, as against whatever other reinforcers are available to the animal but not under experimenter control. If $r_{0}$ is the aggregate of nonexperimentally controlled reinforcement, and $R_{0}$ is non- $R$ responding, then from the development of Equation 2 we have

$$
\frac{\mathbf{R}}{\mathbf{R}+\mathbf{R}_{\mathbf{o}}}=\frac{\mathrm{r}}{\mathrm{r}+\mathrm{r}_{\mathrm{o}}}
$$

And so the matching law holds in single-choice situations.

\section{Inhibitory Effects of Reinforcement}

The ability of reinforcers to strengthen and maintain responses upon which they are contingent may be termed the excitatory effect of reinforcement. An inhibitory effect of reinforcement is also demonstrable. In a two-choice situation, when the reinforcement rate for the first response is increased, the rate of the second response decreases, even though the reinforcement rate for this second alternative has not changed. This decrease in responding may be termed a reinforcer's inhibitory effect (Catania, 1973). The inhibitory effect of reinforcement is different from the excitatory effect in that while the excitatory effect is specific to the response upon which the reinforcer is contingent, the inhibitory effect is nonspecific: it affects all ongoing behavior. By logical extension, a reinforcer contingent upon response $A$ can be considered to have not only an excitatory effect upon A, but also an inhibitory effect upon $\mathrm{A}$ as well.

Quantitatively speaking, the standard interpretation assumes that an essentially constant level of responding, $\mathrm{k}$, is distributed among the alternative responses available to the animal. In single-response situations, the monotonically increasing negatively accelerated function (Equation 1) occurs as reinforcement for the single response increases because $\mathrm{r}_{\mathrm{o}}$, the total nonexperimental sources of reinforcement, comprises a decreasing proportion of the total reinforcement. The alternative interpretation assumes responding to be a linear function of reinforcement. But, as reinforcement increases, inhibition increases, resulting in a response ceiling. The form of Catania's equation is almost identical to that of Herrnstein, except for a constant that appears in both the numerator and denominator of the expression:

$$
\mathrm{R}=\frac{\mathrm{kcr}}{\mathrm{r}+\mathrm{c}},
$$

where $\mathrm{c}$ is the constant of inhibition. Although the quantity $\mathrm{kc}$ in the numerator can be combined into another constant to mimic the exact form of the Herrnstein equation, the $\mathrm{c}$ in the numerator has an important consequence.

\section{Restatement of the Inhibition Interpretation}

The present interpretation assumes that responding is a linear function of reinforcement, but that an inhibitory effect of reinforcement reduces responding in proportion to the reinforcement and in proportion to the ongoing responding. If $\mathbf{k}$ and $c$ are constants, $r$ is a measure of reinforcement, and $R$ is a measure of responding, then

$$
\mathrm{R}=\mathrm{kr}-\mathrm{cr} \mathbf{R} \text {. }
$$

Solving Equation 4 for R:

$$
\mathrm{R}=\frac{\mathrm{kr}}{1+\mathrm{cr}} \text {. }
$$

Letting $c=1 / c^{\prime}$,

$$
R=\frac{k r\left(c^{\prime}\right)}{\left(1+r / c^{\prime}\right)\left(c^{\prime}\right)}=\frac{k c^{\prime} r}{r+c^{\prime}},
$$

which is Catania's form of the Herrnstein equation.

Equation 4 is offered as a general replacement for Equations 1 and 3 . It is more revealing about the nature of the inhibitory effect of reinforcement, that is, it operates on the ongoing behavior as a kind of damping mechanism, attenuating a reinforcer's excitatory effects. This inhibition of responding in proportion to the reinforcement and the ongoing responding produces a ceiling on the response-reinforcement input-output function. ${ }^{1}$

Figure 1 illustrates the dynamic nature of this inhibition in a single-response situation. Figure 2 generalizes the equation to a choice situation. Because reinforcers selectively excite only those response alternatives upon which they are contingent while

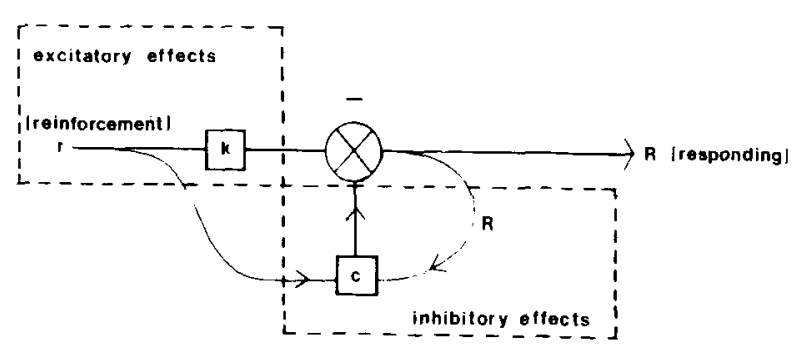

Figure 1. The dynamics of the excitatory and inhibitory effects of reinforcement. A given reinforcement magnitude ( $r$ ) is multiplied by $k$ to give the total excitatory effect. This amount is then fed back to the system, multiplied by $c$ and $r$, and subtracted from the excitatory effect. Thus, the final output, responding $(R)$, is the excitatory value damped by an amount proportional to the reinforcement and to the output. 


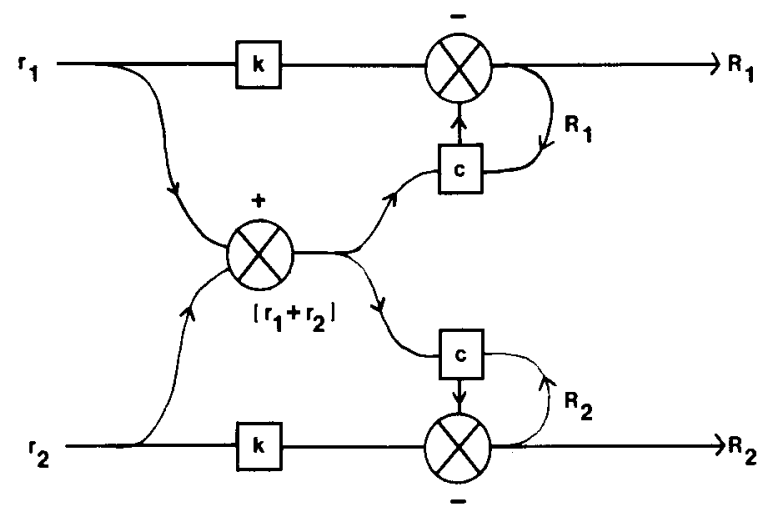

Figure 2. The dynamics of a two-choice situation. The excitatory effect of reinforcement is specific to the response upon which that reinforcement is contingent. But the inhibitory damping effect is proportional to the total amount of reinforcement $\left(r_{1}+r_{2}\right)$. The result is a system that preserves the matching law.

inhibiting all responding nonspecifically, the equations for the two responses are:

$$
R_{1}=k r_{1}-c\left(r_{1}+r_{2}\right) R_{1} ; \quad R_{2}=k r_{2}-c\left(r_{1}+r_{2}\right) R_{2} .
$$

This mechanism, selectively exciting responding in proportion to the contingent reinforcement, but nonselectively inhibiting in proportion to the reinforcement and to ongoing responding, results in behavior that preserves the matching law. Unlike the standard interpretation, the inhibition interpretation yields matching without first assuming it.

\section{From Discrete to Distributed}

\section{Response-Reinforcer Situations}

The Herrnstein equation is appropriate to reinforcement measures that are either momentary (concentration of sucrose, intensity of brain stimulation, amount of food) or distributed in time (reinforcement rate). It is also appropriate for response measures that are either momentary (reaction speed; speed of alleyway running or swimming) or distributed in time (response rate). A concern for how a performance mechanism can yield the same function relating responding to reinforcement when the independent and dependent variables are either momentary or distributed will lead to a possible solution of the problem of fixed-interval performances.

Since Equation 4 holds for variable-interval reinforcement schedules, the number of responses that a single reinforcer will sustain on such a schedule can be determined. Dividing $R$, the response rate, by $r$, the reinforcement rate, to obtain $N$, the number of responses per reinforcer, we get:

$$
\mathbf{N}=\mathrm{k}-\mathrm{cR} \text {. }
$$

That is, the number of responses generated per reinforcer is a constant $\mathrm{k}$ minus a number proportional to the ongoing response rate. This means that an animal responds at a rate such that the number of responses generated by that rate over the average interreinforcement interval is a constant minus an amount proportional to that particular rate.

\section{Fixed-Interval Responding}

When reinforcers are made available at periodic intervals, animals begin to respond within that interval well before their capacity to discriminate temporal durations would predict (Catania \& Reynolds, 1968; Dews, 1970; Gibbon, 1977; Jenkins, 1970). Responding typically accelerates over the course of the interval, reaching a maximum (terminal) rate just before reinforcer delivery. An important consideration is that the animal's judgment of time is apparently proportional to the interval length, i.e., the shape of the fixed-interval scallop is invariant with respect to the relative duration of the interval, although the absolute response rate is a decreasing function of the absolute interval duration (Dews, 1970; Gibbon, 1977; Killeen, 1975). The present problem is to find a suitable expression for this shape that embodies the Herrnstein equation, or rather, the generalized form of the Herrnstein equation, Equation 4. We are interested in finding an expression that relates the shape of the fixed-interval scallop to the input-output function derived from the excitatory and inhibitory effects of reinforcement.

The present model assumes that a reinforcer can sustain a large number of responses, and that a reinforcer's ability to sustain responding increases over the fixed interval. In other words, we assume that a reinforcer effectively "spreads" its ability to sustain responding over the interval. This is not to imply a delay-of-reinforcement gradient stretching over the interval, but only to recognize that responses emitted at the early part of the fixed-interval occur because of the reinforcer at the end of the interval. Because fewer responses occur at the start of the interval than in the later parts, we could say that a reinforcer's strength is minimal at the start of the interval, but grows according to some function to a maximum value at the end of the interval. The present model assumes the simplest of growth functions: if $\mathrm{S}$ is the momentary strength of the reinforcer at any point in the interval, then the rate of change of $S$ over the interval is proportional to $\mathrm{S}(\mathrm{dS} / \mathrm{dt} \propto \mathrm{S})$. This is equivalent to saying that the strength of the reinforcer increases exponentially over the interval, or that $S=k^{\alpha t}$. (It is also mathematically equivalent to assuming an exponentially decreasing retroactive effect of the reinforcer upon responses occurring before the reinforcer.) However, because an animal's judgment of a reinforcer's strength is relative to the total interval length (proportionate timing), the suggested growth function is:

$$
\mathrm{S}=\mathrm{ke}^{\mathrm{at} / \mathrm{i}} \text {, }
$$


where $t$ is the absolute time into the fixed interval, and $i$ is the fixed-interval duration. The function says that the strength of a reinforcer is $k$ at the very start of the interval, and grows to a maximum of $\mathrm{ke}^{\alpha}$ at the end of the interval. Let us assume further that the rate of responding is proportional to the rate at which the momentary strength of the reinforcer is changing, that is, that $\mathrm{R} \propto \mathrm{dS} / \mathrm{dt}$. That is, the rate of responding over the interval (ignoring inhibitory effects for the moment) will be:

$$
R=\frac{d\left(k e^{\alpha t / i}\right)}{d t}=\frac{k \alpha e^{\alpha t / i}}{i}
$$

And the total number of responses emitted over the interval is:

$$
\mathrm{N}=\int_{0}^{\mathrm{i}} \frac{\mathrm{k} \alpha \mathrm{e}^{\alpha \mathrm{t} / \mathrm{i}}}{\mathrm{i}} \mathrm{dt}=\left.\mathrm{ke}^{\alpha \mathrm{t} / \mathrm{i}}\right|_{0} ^{\mathrm{i}}=\mathrm{k}\left(\mathrm{e}^{\alpha}-1\right) .
$$

Thus, the assumptions of exponential growth of a reinforcer's strength, combined with an animal's proportionate time judgment of the interval, generates a constant $\mathrm{N}$ for all values of $\mathrm{i}$. (This constancy of the number of responses maintained by a given reinforcer is, essentially, the justification for the assumption that the response rate is proportional to the rate of change of $S$, the momentary strength of the reinforcer.)

Assume now a similarly growing inhibitory function: $I=c^{\beta 1 / 1}$, which inhibits responding in proportion to its rate of change ( $\mathrm{dl} / \mathrm{dt}$ ), and in proportion to $\mathrm{R}$. Thus, responding at any point in the interval is:

$$
\mathrm{R}=\frac{\mathrm{k} \alpha \mathrm{e}^{\alpha \mathrm{t} / \mathrm{i}}}{\mathrm{i}}-\frac{\mathrm{c} \beta \mathrm{e}^{\beta \mathrm{t} / \mathrm{i}}}{\mathrm{i}}(\mathrm{R})
$$

or

$$
\mathrm{R}=\frac{\frac{\mathrm{k} \alpha \mathrm{e}^{\alpha \mathrm{t} / \mathrm{i}}}{\mathrm{i}}}{1+\frac{\mathrm{c} \beta \mathrm{e}^{\beta \mathrm{t} / \mathrm{i}}}{\mathrm{i}}} .
$$

Equation 5 should thus give us the typical fixedinterval scallop. Note that the form of the Herrnstein equation is preserved throughout the interval, because the form results from combining excitation and inhibition rather than from the specific growth function assumed to operate within the interval.

How well does Equation 5 fit the data? In Figure 3 , the equation is fit to data from Hawkes and Shimp (1975). Pigeons responded for food on an FI 5 -sec schedule. A computer program selected values of $\mathrm{k}, \alpha, \beta$, and $\mathrm{c}$ that maximized the variance accounted for by the equation. The dashed line indicates the best fit with $c=0$, that is, without the

\section{HAWKES \& SHIMP $\mid 1975]$ FI 5-SEC}

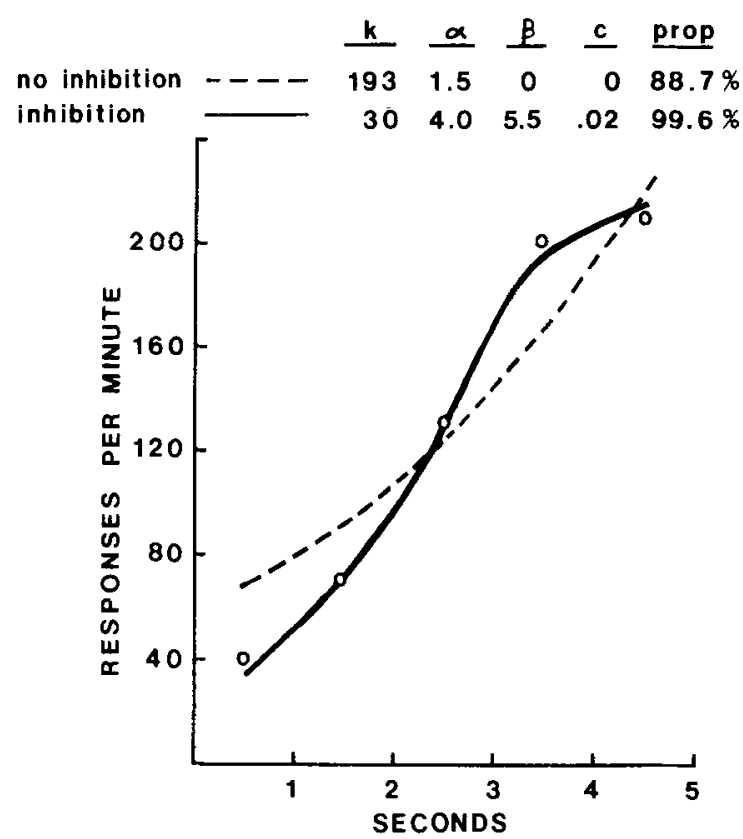

Figure 3. Data from Hawkes and Shimp (1975), who tested pigeons on an FI 5-sec schedule, are fit to two theoretical curves derived from Equation 5 . The dashed curve represents the best fit without the assumption of inhibition, while the solid curve represents the best fit with inhibition. Values for the constants of Equation 5 are indicated in the figure, along with the proportion of the variance accounted for.

assumption of inhibition. The equation without inhibition can account for $88.7 \%$ of the variance. But clearly it does not do justice to the shape of the scallop. The solid line includes inhibition, and the equation then accounts for $99.6 \%$ of the variance.

Dews (1969) trained pigeons on an FI $180-\mathrm{sec}$ schedule, and on an FI 180-sec schedule with a 1-sec unsignaled delay between the response that produced the reinforcer and its presentation. The delay contingency changed the absolute level of responding (the reinforcer's excitatory effect), while having comparatively little effect on the shape of the FI scallop. Equation 5 accounts for $98.5 \%$ of the variance for the no-delay schedule, and $99.4 \%$ of the variance for the delay condition (see Figure 4).

Dukich and Lee (1973) exposed rats to two intervals: an FI 60-sec schedule and an FI 120-sec schedule, using water reinforcement. A single set of parameters for Equation 5 accounted for $98.3 \%$ of the variance for the long and short intervals combined. (See Figure 5.)

The equation fared less well with data from Catania and Reynolds (1968), using three fixed intervals, with pigeons responding for food (Figure 6). A single set of parameters could account for only $84.4 \%$ of the variance for all three intervals combined. Under the assumption that the 200 -sec interval was beyond the point where a linear psychophysical function for time 


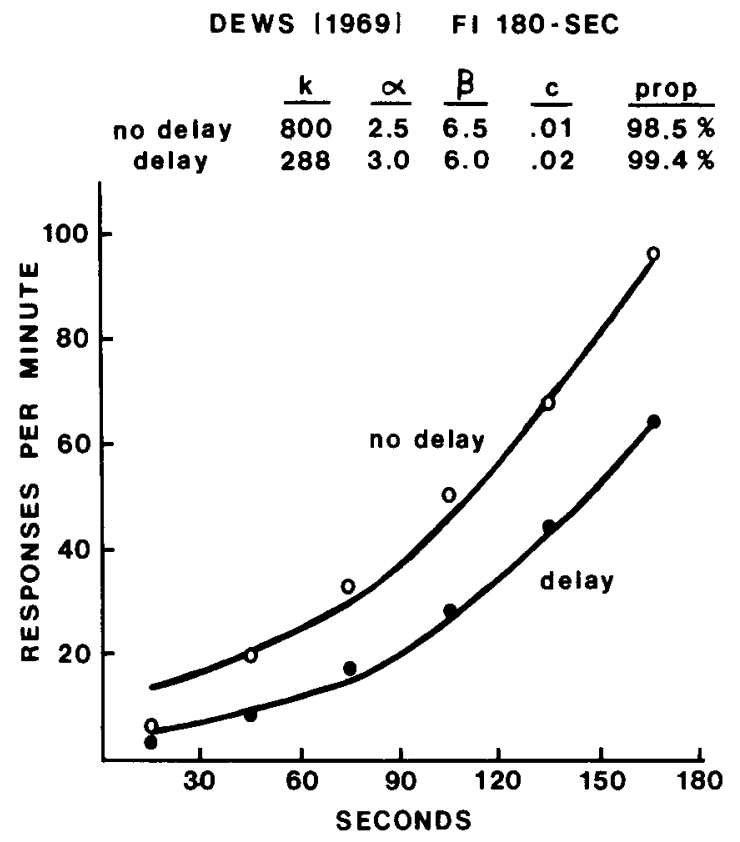

Figure 4. Theoretical fits of Equation 5 to data from Dews (1969). Pigeons were trained on an FI 180-sec schedule (upper curve), and an FI 180-sec schedule with a 1-sec delay of reinforcement (lower curve).

DUKICH \& LEE [1973) TWO INTERVALS

$$
\frac{k}{5.7} \frac{\alpha}{5.5} \frac{\beta}{6.5} \frac{c}{.01} \frac{\text { prop }}{98.3 \%}
$$

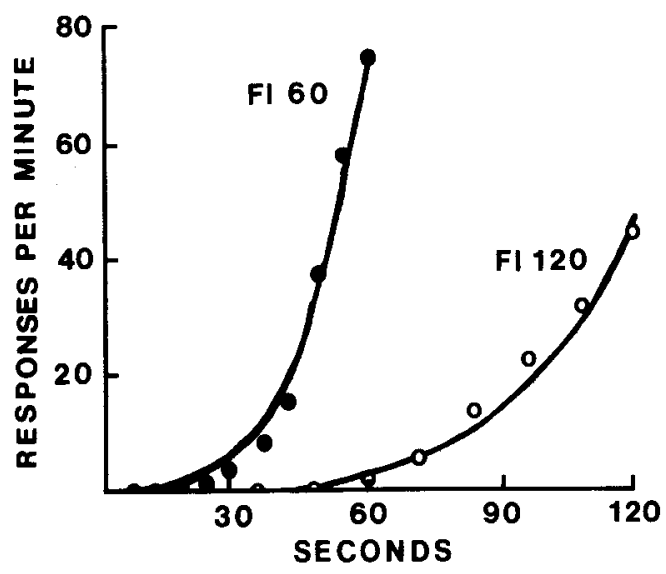

Figure 5. Theoretical fits of Equation 5 to data from Dukich and Lee (1973). Rats were tested on two fixed intervals, 60 and 120. The two data sets were fit with a single set of parameters.

estimation begins to break down (see Catania, 1970; Killeen, 1975), the two shorter intervals were fit to a single set of parameters, accounting for $96.4 \%$ of the variance. The 200 -sec interval was fit by a unique set of parameters that accounted for $95.5 \%$ of the variance. Thus, while Equation 5 does well in accounting for most of the data, it appears to have limitations when a wide range of interval values is encountered.
Killeen (1975) has similarly remarked upon the need to adjust theoretical curves to account for an animal's nonlinear psychophysical judgment of time. This nonlinearity causes animals to make premature judgments of the end of very long intervals, producing a maximal rate of responding before the end of the interval. Following this, responding begins to fall, producing a downturn to the scallop. No further theoretical development is attempted here, however. For discussion of this point, see Catania (1970), Gibbon (1977), and Killeen (1975).

A word should be said about other proposed models of fixed-interval responding. While Killeen's (1975) model is impressive in its ability to account for a single interval, he makes no attempt to simultaneously fit the two intervals of Dukich and Lee, and the three intervals of Catania and Reynolds. It fails, essentially, as a general model because it makes no contact with the Herrnstein equation. The present model's assumption that a reinforcer "spreads" its strength over the response interval in some increasing fashion is similar to Gibbon's theory of expectancy growth, except that a different growth function was chosen (Gibbon, 1977). His model also focuses on that stage of FI performance where the animal essentially produces a break-run pattern of responding rather than a gradually increasing response rate over the interval. The present approach is that the breakrun pattern represents a later development, repre-

CATANIA \& REYNOLDS [1968] THREE INTERVALS
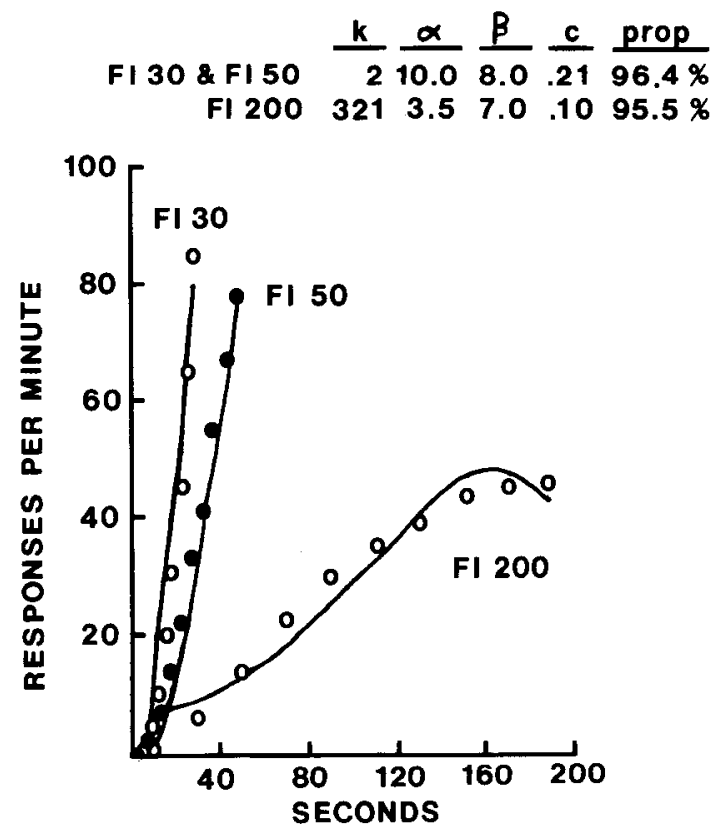

Figure 6. Theoretical fits of Equation 5 to data from Catania and Reynolds (1968). Pigeons were run on three fixed-interval values: 30,50 , and $200 \mathrm{sec}$. The data from the two shorter intervals are fit with the same parameters, while the longest interval was fit with a unique set of parameters. See text for explanation. 
senting an increased control of not responding by the initial, extinction-like period of the fixed interval. As can be seen in Figures 4 and 5 , the theoretical curve is higher than the data points at the initial portions of the fixed interval. This suggests either an additional postreinforcement inhibitory effect or the development of stimulus control by an extinction-like period immediately following reinforcement.

In general, the proposed models of fixed-interval responding to date (e.g., Ambler, 1976; Gibbon, 1977; Killeen, 1975) fail because they do not make contact with the general response-reinforcement input-output function, that is, the Herrnstein equation. The present model assumes that the inhibitory effects of reinforcement derive from the reinforcers provided by the experimenter's reinforcement schedule rather than from extraneous reinforcers as suggested by the standard interpretation. That is, the inhibitory function grows simultaneously with the excitatory function, because the temporal location of the source of the excitation and inhibition (the reinforcer) is identical. If the inhibitory effects emanated from sources of reinforcement other than the scheduled reinforcer, we could not expect the inhibitory effect to be greatest at the moment of reinforcement. In the standard fixed-interval schedule, the inhibitory function can only be inferred, because it is obscured by the more powerful excitatory effect. Nevin (1974), however, has provided an empirical demonstration of the inhibitory function. He ran pigeons on concurrent VI FI schedules. The VI schedule provided a constant response baseline against which to evaluate the effects of the FI reinforcer. As the time to the FI reinforcer grew near, responding gradually decreased on the VI schedule: an elegant demonstration of the growth of the nonspecific inhibitory function of the reinforcer.

\section{The Transition Back to VI}

When reinforcement is made available on a variableinterval schedule, responding is constant rather than scalloped. This constant response rate (not as high as the terminal FI response rate: Dews, 1970; Schneider, 1969) suggests that there is no change in reinforcer strength throughout the interval, that the excitatory and inhibitory growth functions "smooth out" to some constant level. Intuitively, we might suggest that the functions have leveled to a value midway between the initial level of S (the reinforcer's momentary strength) in the fixed-interval case $(k)$ and the terminal value $\left(\mathrm{ke}^{\alpha / \mathrm{i}}\right)$.

By the mean value theorem, and ignoring inhibition for the moment:

$$
R_{V I}=\frac{\int_{0}^{i \frac{k \alpha e^{\alpha t / i}}{i}} d t}{i}=\frac{k\left(e^{\alpha}-1\right)}{i}
$$

This, of course, is just the value obtained by assuming that a single reinforcer generates $\mathrm{N}=\mathrm{k}\left(\mathrm{e}^{\alpha}-1\right)$ responses, distributed over the average interreinforcer interval, i. (The quantity $i$, the interreinforcer interval, is the reciprocal of $r$, the reinforcement rate.) When inhibition is included, VI responding then is:

$$
\mathrm{R}_{\mathrm{V} I}=\frac{\frac{k\left(\mathrm{e}^{\alpha}-1\right)}{\mathrm{i}}}{1+\frac{\mathrm{c}\left(\mathrm{e}^{\beta}-1\right)}{\mathrm{i}}},
$$

which is the Herrnstein equation, including the additional constants e, $\alpha$, and $\beta$ that allow for direct comparison with FI levels of responding.

While this is a consistent result, it lacks detail with respect to the mechanism responsible for smoothing the exponentially growing excitatory and inhibitory functions of the FI to constant VI levels. Some progress in this direction may be suggested by assuming that organisms experienced with such VI schedules treat them as a succession of fixed intervals of arbitrarily small intervals, with an associated probability of reinforcement in each interval (cf. Farmer, 1963; Millenson, 1963). Assume that each interval contains a number of responses proportional to the probability $(p)$ that the interval will end with a reinforcer. Then the number of responses within each small interval of I duration (ignoring inhibitory effects) is

$$
\mathrm{N}_{\mathrm{I}}=\mathrm{pk}\left(\mathrm{e}^{\alpha}-1\right) .
$$

If $n$ such intervals are contained within $i$, the average interreinforcer interval, then the total number of responses in $\mathrm{i}$ is

$$
\mathrm{N}=\sum_{\mathrm{a}=1}^{\mathrm{n}} \mathrm{p}_{\mathrm{a}} \mathrm{k}\left(\mathrm{e}^{\alpha}-1\right)=\mathrm{k}\left(\mathrm{e}^{\alpha}-1\right),
$$

since

$$
\sum_{a=1}^{n} p_{a}=1
$$

The average response rate is, therefore,

$$
\mathrm{R}=\frac{\mathrm{N}}{\mathrm{i}}=\frac{\mathrm{k}\left(\mathrm{e}^{\alpha}-1\right)}{\mathrm{i}} .
$$

Similar reasoning applies to the inhibitory function, and the rate of VI responding is as in Equation 5.

If $I$ is very small, the resulting response rate may just reflect the average rate, i.e., the exponentially 
increasing scallop may go unobserved or may be washed out on output because of the variability with respect to an animal's timing of the smallest intervals. But if experimental conditions are such that the distribution of interreinforcer intervals does not approximate a constant probability, then marked departures from constant responding would be observed. Catania and Reynolds (1968) manipulated probabilities in this fashion and in fact observed response rates to be sensitive to this variable.

\section{Summary and Extension to Nonoperant Studies}

Catania's interpretation of the Herrnstein equation implies that reinforcers excite responding in proportion to their magnitude but also inhibit responding in proportion to both their magnitude and the magnitude of the ongoing responding. Such a performance mechanism preserves the matching law when more than one response is available. Combined with the assumption of proportionate timing of intervals and an exponential growth of excitation and inhibition across the fixed interval, that interpretation generates a quantitative description of the fixed-interval scallop, rendering the standard interpretation of $r_{o}$ less plausible.

One point needs further clarification. Reinforcement rate ( $r$ ) and response rate ( $R$ ) are suitable independent and dependent variables in the Herrnstein equation because a single reinforcer has the ability to support a number of responses. These responses are distributed as a rate because they must be emitted within the interreinforcement interval. However, a single reinforcer also has a magnitude-amount or concentration, for example. And, thus, Equation 4 needs to be expanded to include the absolute magnitude of the reinforcer as well as the reinforcement rate. Since behavioral studies that do not use reinforcement rate as a parameter also conform to the Herrnstein equation, the suggested amendation is:

$$
\mathrm{R}=\mathrm{kar}-\operatorname{car} \mathbf{R},
$$

where $a$ is the single reinforcer quantity. In the fixedinterval case:

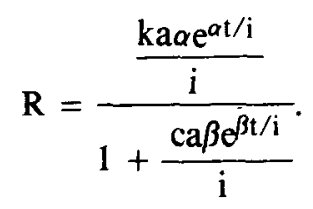

Here the quantity a interacts with $\mathrm{k}$ and $\mathrm{c}$ to determine the level the excitatory and inhibitory growth functions will reach. The quantity $r$, reinforcement rate, acts in a different manner. Since $r$ is the reciprocal of $i$, the interreinforcer interval, it effectively sets the temporal limits within which a given number of responses must be "squeezed." And so, although the mechanisms whereby the quantities a and $r$ act to produce given levels of responding are different, both enter into the equation as multipliers of the excitation and inhibition. In situations where it is inappropriate to include the quantity $r$, as in runway or discrete trial studies, the general equation is simply

$$
\mathrm{R}=\mathrm{ka}-\mathrm{caR} \text {. }
$$

The form of the equation is nevertheless preserved in studies that do not involve reinforcement rate or response rate as the independent and dependent variables.

\section{REFERENCES}

Ambler, S. A comparison of two models for performance under fixed interval schedules of reinforcement. Journal of Mathematical Psychology, 1976, 14, 53-71.

BaUM, W. M. On two types of deviation from the matching law: Bias and undermatching. Journal of the Experimental Analysis of Behavior, 1974, 22, 231-242.

Catania, A. C. Concurrent performances: Reinforcement interaction and response independence. Journal of the Experimental Analysis of Behavior, 1963, 6, 253-263. (a)

Catania, A. C. Concurrent performances: A baseline for the study of reinforcement magnitude. Journal of the Experimental Analysis of Behavior, 1963, 6, 299-300. (b)

Catania, A. C. Reinforcement schedules and psychophysical judgments. In W. N. Schoenfeld (Ed.) The theory of reinforcement schedules. New York: Appleton-Century-Crofts, 1970.

Catania, A. C. Self-inhibiting effects of reinforcement. Journal of the Experimental Analysis of Behavior, 1973, 19, 517-526.

Catania, A. C., \& Reynolds, G. S. A quantitative analysis of the responding maintained by interval schedules of reinforcement. Journal of the Experimental Analysis of Behavior, 1968, $11,327-383$.

Chung, S.-H., \& Herrnstein, R. J. Choice and delay of reinforcement. Journal of the Experimental Analysis of Behavior, $1967,10,67-74$.

DE Villie rs, $P$. Choice in concurrent schedules and a quantitative formulation of the law of effect. In W. K. Honig \& J. E. R. Staddon (Eds.), Handbook of operant behavior. Englewood Cliffs, N.J: Prentice-Hall, 1977.

deVilliers, P. A., \& Herrnstein, R. J. Toward a law of response strength. Psychological Bulletin, 1976, 83, 1131-1153.

Dews, P. B. Studies on responding under fixed-interval schedules of reinforcement: The effects on the pattern of responding of changes in requirements at reinforcement. Journal of the Experimental Analysis of Behavior, 1969, 12, 191-199.

Dews, P. B. The theory of fixed-interval responding. In W. N. Schoenfeld (Ed.), The theory of reinforcement schedules. New York: Appleton-Century-Crofts, 1970.

DukiCH, T. D., \& LEE, A. E. A comparison of measures of responding under fixed-interval schedules. Journal of the Experimental Analysis of Behavior, 1973, 20, 281-290.

Farmer, J. Properties of behavior under random interval reinforcement schedules. Journal of the Experimental Analysis of Behavior, 1963, 6, 607-616.

GıBвon, J. Scalar expectancy theory and Weber's law in animal training. Psychological Review, 1977, 84, 279-325.

Hawkes, L., \& Shimp, C. P. Reinforcement of behavioral patterns: Shaping a scallop. Journal of the Experimental Analysis of Behavior, 1975, 23, 3-16. 
HERrNSTEIN, R. J. Relative and absolute strength of response as a function of frequency of reinforcement. Journal of the Experimental Analysis of Behavior, 1961, 4, 267-272.

Herrnstein, R. J. On the law of effect. Journal of the Experimental Analysis of Behavior, 1970, 13, 243-266.

Herrnstein, R. J. Formal properties of the matching law. Journal of the Experimental Analysis of Behavior, 1974, 21, 159-164.

Herrnstein, R. J., \& Heyman, G. M. Is matching compatible with reinforcement maximization on concurrent variable interval, variable ratio? Journal of the Experimental Analysis of Behavior, 1979, 31, 209-223.

JENk INS, H. M. Sequential organization in schedules of reinforcement. In W. N. Schoenfeld (Ed.), The theory of reinforcement schedules. New York: Appleton-Century-Crofts, 1970.

KilleEn, P. The matching law. Journal of the Experimental Analysis of Behavior, 1973, 17, 489-495.

KilleEn, P. On the temporal control of behavior. Psychological Review, 1975, 82, 89-115.

Luce, R. D. The choice axiom after twenty years. Journal of Mathematical Psychology, 1977, 15, 215-233.

McDowell, J. J., \& Kessel, R. A multivariate rate equation for variable-interval performance. Journal of the Experimental Analysis of Behavior, 1979, 31, 267-283.

Millenson, J. R. Random interval schedules of reinforcement. Journal of the Experimental Analysis of Behavior, 1963, 6 . 437-443.

Nevin, J. A. On the form of the relation between response rates in a multiple schedule. Journal of the Experimental Analysis of Behavior, 1974, 21, 237-248.

PEar, J. J. Implications of the matching law for ratio responding. Journal of the Experimental Analysis of Behavior, 1975, 23, 139-140.
RACHLIN, H. C. On the tautology of the matching law. Journal of the Experimental Analysis of Behavior, 1971, 15, 249-251.

RACHLIN, H. C. A molar theory of reinforcement. Journal of the Experimental Analysis of Behavior, 1978, 30, 345-360.

Schneider, B. A. A two-state analysis of fixed-interval responding in the pigeon. Journal of the Experimental Analysis of Behavior, 1969, 12, 677-687.

Staddon, J. E. R. On Herrnstein's equation and related forms. Journal of the Experimental Analysis of Behavior, 1977, 28, $163-170$.

\section{NOTE}

1. It has been suggested that the response ceiling reflects a limitation on the animal's ability to respond at high rates, a kind of natural ceiling due to the time it takes a response to be executed (e.g., Staddon, 1977). Such an interpretation is here considered unlikely, since animals are able to emit exceptionally high response rates under different reinforcement schedules (e.g., ratio, differential reinforcement of high rates). Ratio schedules are not considered in the present treatment, although a suitably modified version of the Herrnstein equation is apparently appropriate as a description of performances generated by ratio schedules (Herrnstein \& Heyman, 1979; Pear, 1975). The range of response measures that conform to the Herrnstein equation also renders the interpretation of a response ceiling based upon the time necessary to emit a response unlikely.

(Received for publication June 25, 1979; revision accepted September 29, 1979.) 